Original Research Paper

\title{
Simplified Analysis of the Lining Behavior During Earthquakes in Deep Rock Tunnels
}

\author{
Pierpaolo Oreste \\ Department of Environmental, Land and Infrastructural Engineering, \\ Politecnico di Torino, Corso Duca Degli Abruzzi 24, I-10129 Torino, Italy
}

Article history

Received: 17-03-2015

Revised: 09-04-2015

Accepted: 15-04-2015

\begin{abstract}
The sizing of the lining of a tunnel requires to consider not only the static loads transmitted from the surrounding rock, but also the effects of earthquakes on the stresses and strains of the lining. The detailed evaluation of the interaction earthquake-lining using numerical methods typically requires very long calculation time and can be limited to the verification of the project final configuration. In this study a simplified procedure for the assessment of the effects of an earthquake on the tunnel lining is presented. This procedure is based on the calculation method Einstein and Schwartz and quickly allows the estimation of maximum moments induced by the earthquake in the lining. Through this procedure it was possible to develop a parametric analysis that allowed to evaluate the pseudo-static loads that is necessary to consider on the rock around the tunnel, according to the earthquake characteristics and to the geomechanic quality of the rock mass. A final calculation example illustrates the modalities for the analysis of a tunnel lining in the presence of a defined earthquake, using the charts developed in the present paper.
\end{abstract}

Keywords: Tunnel Lining, Deep Tunnel, Circular Tunnel, Dynamic Effect on the Tunnel, Earthquake Action on the Structure, Shear Wave, Concrete Lining, Shear Strain, Wave Propagation Velocity, Peak Particle Velocity, Peak Particle Acceleration

\section{Introduction}

The analysis of an earthquake effect on the concrete lining is an important stage of the tunnel design (Power et al., 2004). Sophisticated numerical methods allow assessing in the detail the interaction between seismic waves and tunnel linings (Karakostas and Manolis, 2000; Penzien and $\mathrm{Wu}, 1998$; Penzien, 2000; Hashash et al., 2001; Do et al., 2015). The two and three dimensional numerical methods are widespread in the field of tunnels and underground works in general for many years (Do et al., 2013; Oreste, 2002; Do et al., 2014a; 2014b). These methods are, however, quite complex and may require very long computation times when the behavior of the lining and of the rock around the tunnel is analizedin the dynamic field.

The analytical methods, instead, generally provide a closed form solution or a simplified numerical solution, able to assess the stress and strain state of supporting structures or of the rock mass around the tunnel (Ribacchi and Riccioni, 1977; Lembo-Fazio and Ribacchi, 1986; Panet, 1995; Oreste, 2003a; 2003b; 2009a; 2008; Osgoui and Oreste, 2007; 2010) or forward to the excavation face (Oreste, 2009b; 2013; 2014a). In recent times, many analytical methods have been developed in the tunneling field, to resolve static problems of great importance (Oreste, 2007; Do et al., 2014c). The analytical methods require computing time remarkably low and permit, therefore, to develop parametric analyzes (Oreste, 2014b; 2014c), probabilistic ones (Oreste, 2005a) or back-analysis (Oreste, 2005b), all very useful in the design phase or during the construction of a tunnel. In these cases, the use of numerical modeling is limited only to the verification of the final configuration obtained by the dimensioning with analytical methods.

In this study a new simplified analytical procedure for the assessment of the effects of an earthquake on the stress state of the tunnel lining, considering the presence of pseudo-static loads, is presented. After analyzing the magnitude of induced strains around the tunnel by the shear waves due to an earthquake, the formulations to derive the maximum bending moments in the lining, using the Einstein and Schwartz (1979) method, are shown. 
An extensive parametric analysis has then allowed to evaluate the pseudo-static load that is necessary to apply to the rock mass around the tunnel, to account for the presence of an earthquake, according to the intensity of the earthquake (Power et al., 2004), the distance from the source and the GSI of the rock mass (Marinos et al., 2005; Hoek et al., 2013; Marinos and Hoek, 2000; Cai et al., 2004). A calculation example, referring to a specific case, illustrates, finally, the procedures for verification of the lining, considering the loads both of static and dynamic nature (due to the presence of an earthquake).

\section{Materials and Methods}

In deep tunnels realized in a rock mass, the more dangerous seismic waves are represented by the shear waves. These waves have a peak particle velocity $\mathrm{v}_{\mathrm{s}}$, a peak particle acceleration $a_{s}$ and a propagation speed $C_{m}$ that can be obtained from the following equations (Power et al., 2004):

$$
a_{s}=0.7 \cdot a_{\max }\left[\mathrm{m} / \mathrm{s}^{2}\right]
$$

for tunnels at depths greater than $30 \mathrm{~m}$

where, $a_{\max }$ : Maximum particle acceleration due to shear waves, detected on a rocky outcrop at the surface (Sadigh and Egan, 1998; Power et al., 2004):

$$
v_{s}=\beta \cdot \frac{a_{s}}{100 \cdot g}[m / s]
$$

Where:

$$
\begin{aligned}
& \beta \cong\left(0.0020 \bullet M_{W}-0.0166\right) \bullet \\
& d^{2}+\left(-0.0622 \cdot M_{W}^{2}+0.7844 \cdot M_{W}-1.7771\right) \bullet \\
& d+\left(-2.8835 \cdot M_{W}^{2}+71.036 \bullet M_{W}-279.47\right)
\end{aligned}
$$

$g=9.81 \mathrm{~m} / \mathrm{s}^{2}$

$M_{W}=$ Earthquake intensity

$d=$ distance of the earthquake point source from the tunnel:

$C_{m}=\sqrt{\frac{g \cdot G}{\gamma}}$

Where:

$$
G=\frac{E}{2 \cdot(1+v)}
$$

E: Elastic modulus of the rock mass; for the estimation of this value, is generally used the following formulation, which depends on the GSI, on the disturbance factor $\mathrm{D}$ and on the uniaxial compressive strength of the intact rock $\sigma_{\mathrm{ci}}($ Hoek et al., 2002):

$$
\begin{aligned}
& E=\sqrt{\frac{\sigma_{c i}}{100}} \cdot\left(1-\frac{D}{2}\right) \cdot 10^{\left(\frac{G S I-10}{40}\right)} \operatorname{per} \sigma_{\mathrm{ci}}<100 \mathrm{MPa} \\
& E=\left(1-\frac{D}{2}\right) \cdot 10^{\left(\frac{G S I-10}{40}\right)} \operatorname{per} \sigma_{\mathrm{ci}} \geq 100 \mathrm{MPa}
\end{aligned}
$$

$v=$ Poisson ratio of the rock mass

$\gamma=$ Specific weight of the rock

In the case of deep tunnel and for wavelength larger than the tunnel diameter, on the basis of $\mathrm{v}_{\mathrm{s}}$ and $\mathrm{C}_{\mathrm{m}}$ is possible to obtain an estimate of the maximum shear strain induced in the rock mass around the tunnel (Power et al., 2004):

$\gamma_{s, \max }=\frac{v_{s}}{C_{m}}$

This maximum shear strain, when multiplied by the shear deformation modulus $\mathrm{G}$, allows to obtain the shear stresses acting on the rock, or directly the normal stresses applied to the rock around the tunnel, according to the simplified load scheme of Fig. 1 (El Naggar et al., 2008; Penzien and Wu, 1998):

$q_{d y n}=\gamma_{s, \max } \cdot G$

The lining ovalization produced by the shear wave is critical when the direction of the wave is equal to $\lambda= \pm \pi / 4$ with respect to the vertical direction. In that case the maximum moment that develops in the crown or on the sides of the tunnel due to the presence of an earthquake, is added to the maximum moment due to static loads.

The maximum moment produced by the load scheme of Fig. 1 can be evaluated with the method of Einstein and Schwartz (1979). This method provides a closed form solution of the stress state in the lining; it considers the medium around the tunnel as homogeneous and isotropic with an elastic behavior. The state of stress is applied to the ground at a great distance from the tunnel. The lining is represented by a closed ring with its own axial and flexural stiffnesses which depend on the constituent material elastic modulus and the lining thickness.

Adopting the solution of Einstein and Schwartz (1979), which refers to an allowed relative displacement lining-rock (full slip case), the maximum moment that develops in the crown (when the angle $\lambda= \pm \pi / 4$ ) is obtained:

$M_{\max }=q_{d y n} \cdot R^{2} \cdot\left(1-2 \cdot a_{2}^{*}\right)$ 


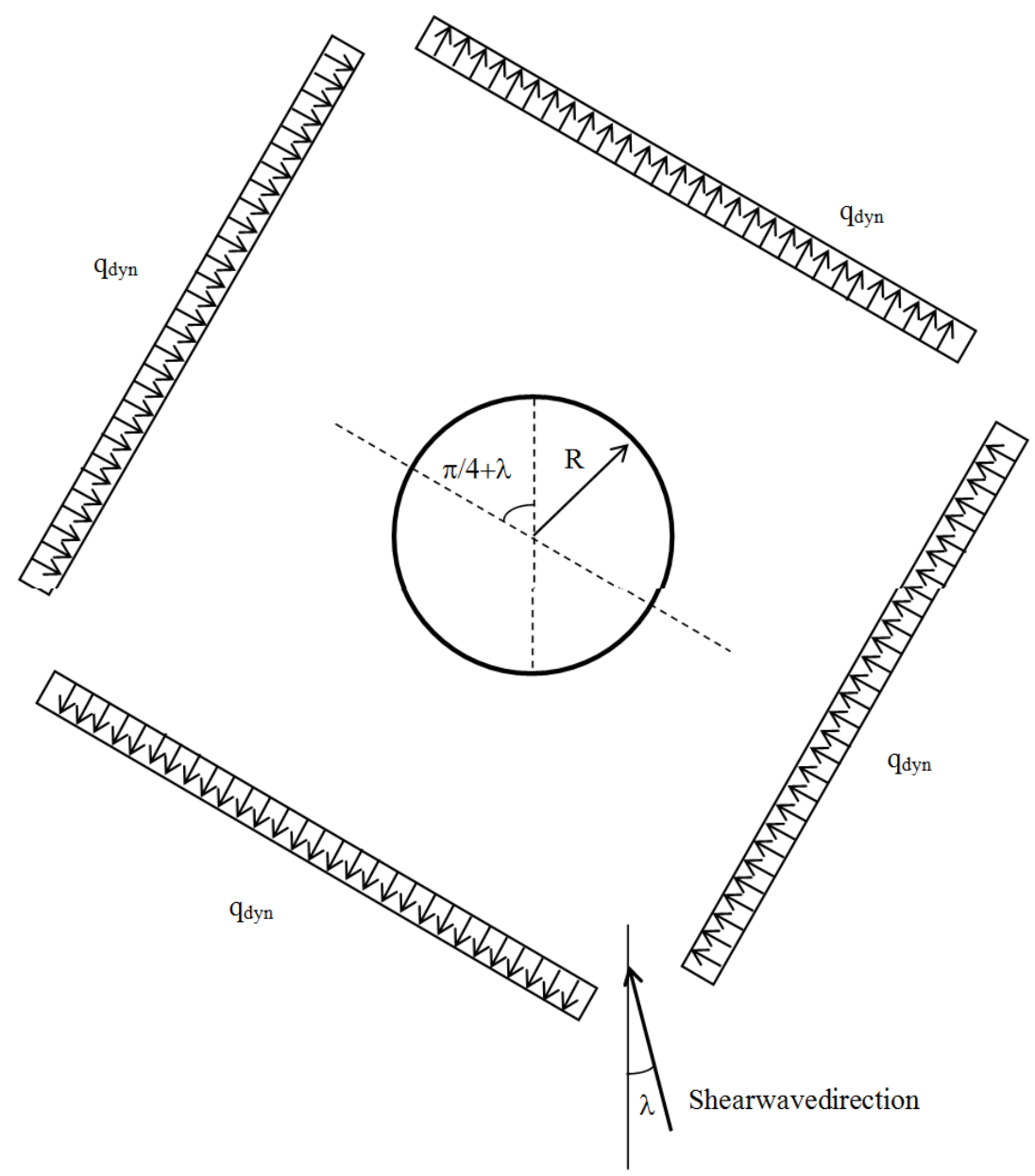

Fig. 1. Simplifiedload scheme of the rock around the tunnel, to simulate the dynamic effects of the presence of an earthquake on the lining of a circular and deep tunnel. Key: $\mathrm{q}_{\mathrm{dyn}}$ is the normal stress that simulates the presence of an earthquake; R: The tunnel radius (El Naggar et al., 2008; Penzien and $\mathrm{Wu}, 1998$ )

where, $a_{2}^{*}$ is a dimensionless coefficient:

$$
\begin{aligned}
& a_{2}^{*}=\frac{\left(F^{*}+6\right) \cdot(1-v)}{2 \cdot F^{*} \cdot(1-v)+6 \cdot(5-6 \cdot v)} \\
& C^{*}=\frac{E \cdot R \cdot\left(1-v_{\text {sup }}^{2}\right)}{E_{\text {sup }} \cdot A_{\text {sup }} \cdot\left(1-v^{2}\right)} F^{*}=\frac{E \cdot R^{3} \cdot\left(1-v_{\text {sup }}^{2}\right)}{E_{\text {sup }} \cdot I_{\text {sup }} \cdot\left(1-v^{2}\right)}
\end{aligned}
$$

$$
\begin{array}{ll}
\mathrm{A}_{\text {sup }} & =\text { The area of the lining section: } \mathrm{A}_{\text {sup }}= \\
& \mathrm{t}_{\text {sup }} \cdot 1 \\
\mathrm{I}_{\text {sup }} & =\text { The inertia moment of the lining section: } \\
& \mathrm{I}_{\text {sup }}=\mathrm{t}_{\text {sup }} \cdot 1 / 12
\end{array}
$$

According to the Einstein and Schwartz analytical method (Einstein and Schwartz, 1979) and for the assumptions made, in particular for the eligibility of lining-tunnel wall relative displacements (full slip case), the normal forces induced by the earthquake in the lining are everywhere equal to zero. That fact is a consequence of the simplified calculation model adopted: Actually values of normal force, even if low and negligible, can be detected even when it is allowed a lining-rock relative displacement.

The presence of an earthquake, therefore, could produce an increase of the positive moment in the crown, leading to an aggravation of the stress conditions of the lining.

It is, therefore, essential to be able to assess with a certain precision the effect of an earthquake on the stress state of the tunnel lining, with particular reference to what can happen on the crown, when the direction of the wave has an angle $\lambda= \pm \pi / 4$ with respect to the vertical.

\section{Results}

In order to evaluate the trend value of the normal stresses $\mathrm{q}_{\mathrm{dyn}}$ due to an earthquake varying the parameters most influential, a parametric analysis was performed 
considering five different values of Geological Strength Index (GSI) (GSI = 40 to 80) (Marinos et al., 2005; Hoek et al., 2013; Marinos and Hoek, 2000; Cai et al., 2004), three values of the maximum particle acceleration $\mathrm{a}_{\max }\left(\mathrm{a}_{\max }=0.4\right.$ to $\left.0.6 \cdot \mathrm{g}\right), 5$ values of the earthquake intensity $(\mathrm{MW}=6.5$ to 8.5$)$ and different values of the distance from the source $(\mathrm{d}=10$ to $100 \mathrm{~km})$ (Power et al., 2004).

In the parametric analysis has been considered a strength of the intact rock $\sigma_{\mathrm{ci}}$ variable with the GSI: $\sigma_{\mathrm{ci}}=35$ $\mathrm{MPa}$ for GSI $=40 ; \sigma_{\mathrm{ci}}=60 \mathrm{MPa}$ for $\mathrm{GSI}=50 ; \sigma_{\mathrm{ci}}=85 \mathrm{MPa}$ for $\mathrm{GSI}=60 ; \sigma_{\mathrm{ci}}=110 \mathrm{MPa}$ for GSI $=70 ; \sigma_{\mathrm{ci}}=135 \mathrm{MPa}$ for GSI = 80 (Hoek and Brown, 1980; 1997; Hoek, 2006; 2007). The disturbance factor $D$ was considered equal to zero, assuming a rock mass not disturbed by the excavation of the tunnel (Hoek et al., 2002).

In Fig. 2-6 are shown the results of the parametric analysis.

It is noted as $\mathrm{q}_{\mathrm{dyn}}$ tends to increase with the increase of the geomechanical properties of the rock mass (i.e., the value of GSI), with the increase of the distance from the earthquake source and obviously with the increase of the maximum particle acceleration on the surface and of the earthquake intensity. Figures 2-6 can be used for the estimation of $\mathrm{q}_{\mathrm{dyn}}$ also for intermediate values of the influential parameters, different from those considered in the parametric analysis, through the use of the linear interpolation.
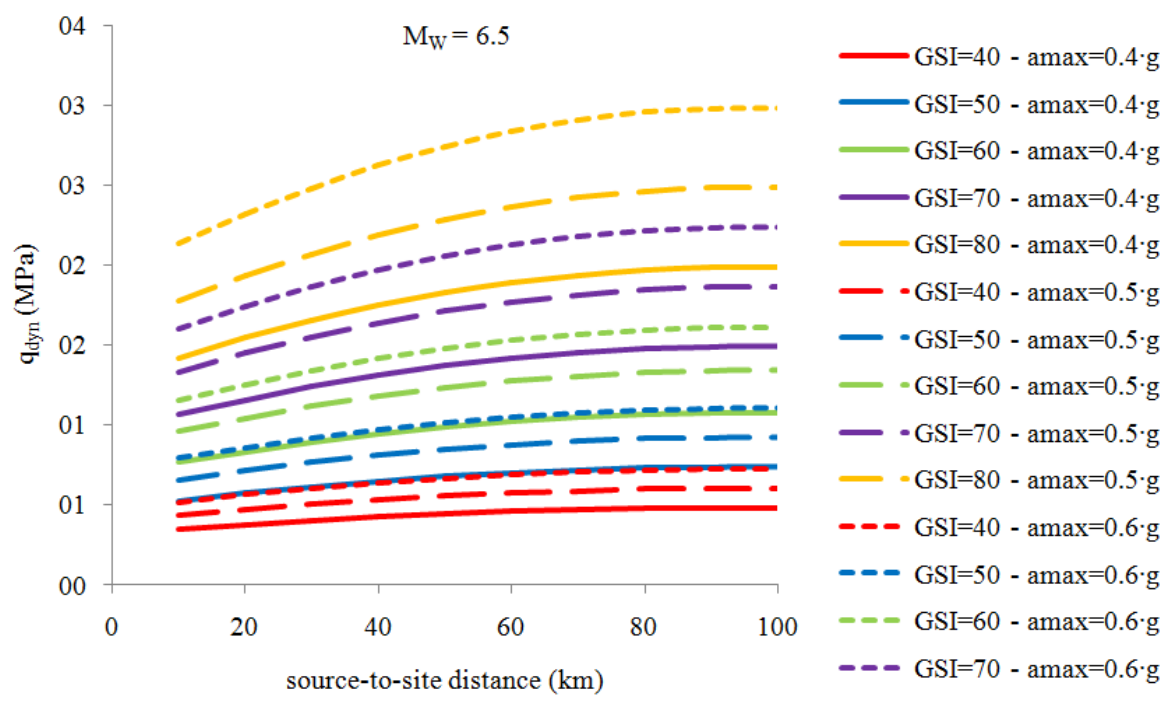

Fig. 2. $\mathrm{q}_{\mathrm{dyn}}$ load trendvarying the distance $\mathrm{d}$ from the earthquake source, the GSI and the maximum particle acceleration on the surface, for an earthquake intensity of $\mathrm{M}_{\mathrm{W}}=6.5$
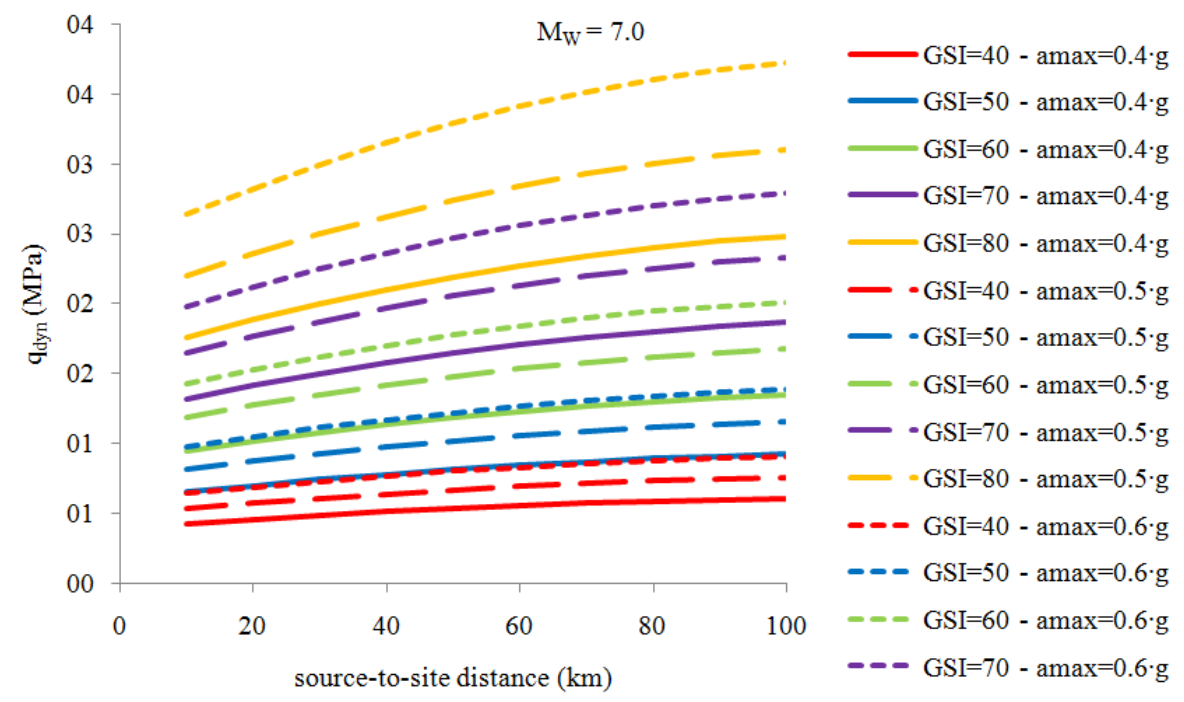

Fig. 3. $\mathrm{q}_{\mathrm{dyn}}$ load trendvarying the distance $\mathrm{d}$ from the earthquake source, the GSI and the maximum particle acceleration on the surface, for an earthquake intensity of $\mathrm{M}_{\mathrm{W}}=7.0$ 

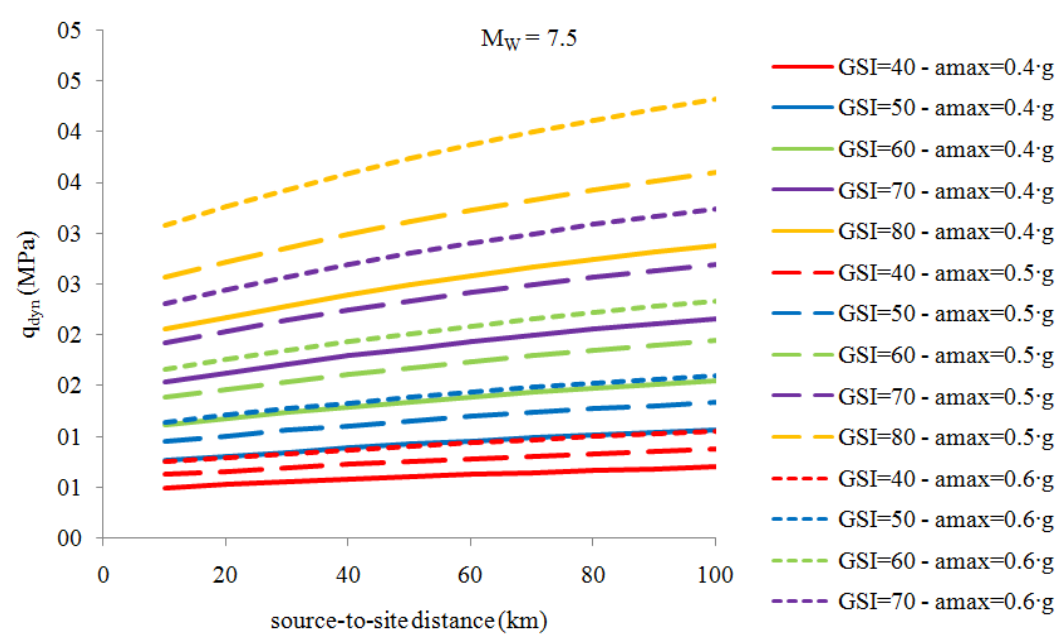

Fig. 4. $\mathrm{q}_{\mathrm{dyn}}$ load trendvarying the distance $\mathrm{d}$ from the earthquake source, the GSI and the maximum particle acceleration on the surface, for an earthquake intensity of $\mathrm{M}_{\mathrm{W}}=7.5$
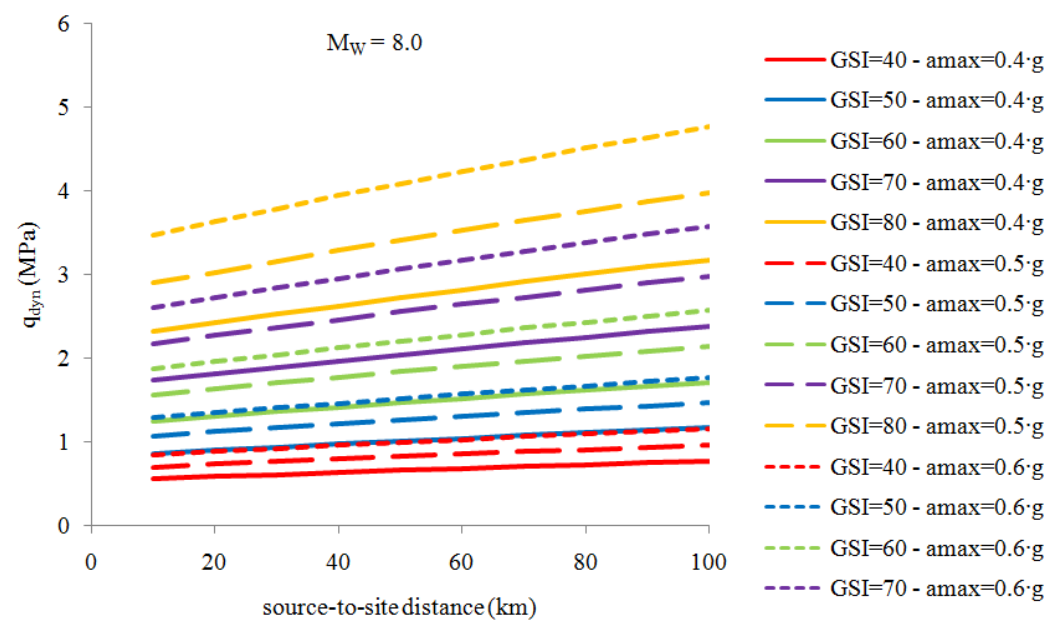

Fig. 5. $q_{\text {dyn }}$ load trendvarying the distance $d$ from the earthquake source, the GSI and the maximum particle acceleration on the surface, for an earthquake intensity of $\mathrm{M}_{\mathrm{W}}=8.0$

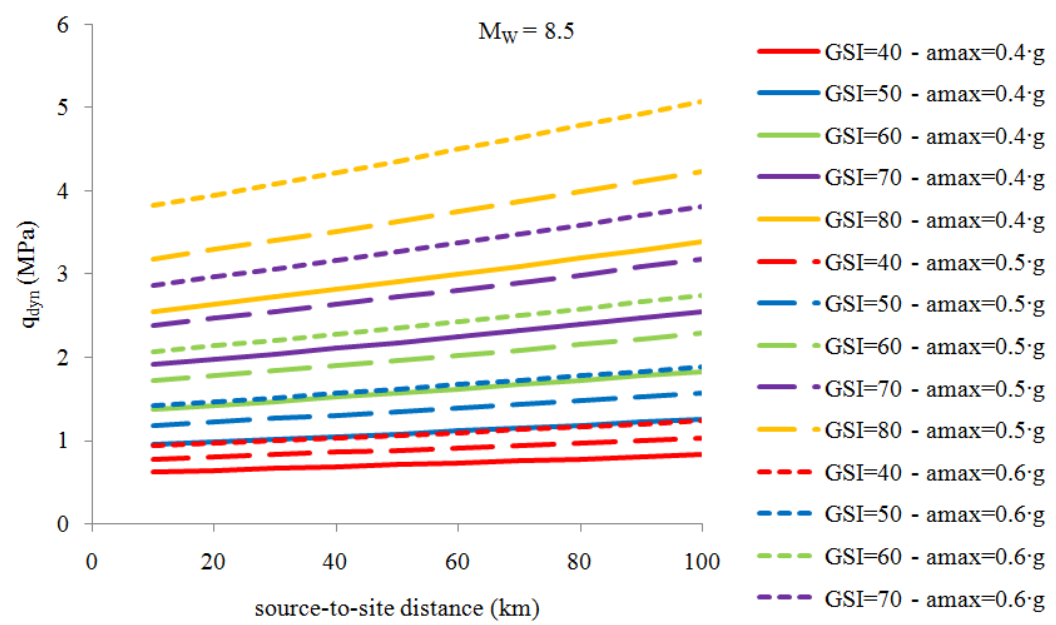

Fig. 6. $\mathrm{q}_{\mathrm{dyn}}$ load trend varying the distance $\mathrm{d}$ from the earthquake source, the GSI and the maximum particle acceleration on the surface, for an earthquake intensity of $\mathrm{M}_{\mathrm{W}}=8.5$ 


\section{Discussion}

From the carried out study, it is noted that the loads acting on the lining are greater when the geomechanic quality of the rock mass is better and, therefore, when its stiffness is higher. The dynamic effects of the earthquake are greater, then, when the static loads are lower. In fact, in a tunnel excavated in a rock mass of good quality, the static loads applied to the lining are generally modest, while the dynamic effects of an earthquake can produce loads that are likely to become critical for the stability of the lining and, therefore, also of the tunnel.

Also the tunnel radius is an important parameter. The moments due to the presence of a seismic wave, in fact, depend on the square of the tunnel radius.

In order to illustrate how to check the effect of an earthquake on a concrete lining of a circular and deep tunnel excavated in a rock mass, the following calculation example, based on the results of Fig. 2-6, is shown.

It refers to a tunnel radius of $3.5 \mathrm{~m}$, excavated into a rock mass with GSI $=55$ at a depth of $200 \mathrm{~m}\left(\mathrm{p}_{0}=5.2\right.$ $\mathrm{MPa}$ ). The uniaxial compressive strength of the intact rock is equal to $72 \mathrm{MPa}$ and the rock mass disturbance factor D is equal to 0 . The elastic modulus for the rock mass is estimated to be $11315 \mathrm{MPa}$ (Hoek et al., 2002) and Poisson's ratio $v=0.3$. Also the following parameters for cohesion $(2.88 \mathrm{MPa})$ and friction angle of the rock mass $\left(27^{\circ}\right)$ (Hoek, 2006), relevant for the evaluation of the static load acting on the $40 \mathrm{~cm}$ thick concrete lining (without reinforcing), are evaluated. The study was conducted using the convergence-confinement method (Ribacchi and Riccioni, 1977; Oreste, 2003a; 2009a; $2014 \mathrm{~b} ; 2014 \mathrm{c}$ ) and has led to an estimate of the static vertical load acting on the lining equal to $1.06 \mathrm{MPa}$.

Adopting this value of static load at the crown and a coefficient of lateral thrust $\mathrm{k}_{0}=0.5$ in the Einstein and Schwartz (1979) method (full slip case), it was possible to estimate the maximum moment in the crown due to static loads $\left(\mathrm{M}_{\max , \text { stat }}=0.0336 \mathrm{MN} \cdot / \mathrm{m}\right)$, associated with a normal force $\mathrm{N}=3.65 \mathrm{MN} / \mathrm{m}$. Figure 7 shows the trend of the bending moment in the lining only due to the static load with a variation of $\vartheta$ angle.

Assuming thereafter an earthquake of intensity equal to $\mathrm{M}_{\mathrm{W}}=8.5$, with a distance from the source point of 80 $\mathrm{km}$ and a maximum particle acceleration on the surface $\mathrm{a}_{\max }=0.5 \cdot \mathrm{g}$, from Fig. 6 a dynamic load $\mathrm{q}_{\mathrm{dyn}}$ equal to about $1.85 \mathrm{MPa}$ is obtained. From Equation 6 the maximum moment produced in the crown of the lining by the considered earthquake can then be evaluated: $\mathrm{M}_{\text {max,dyn }}=0.0369 \mathrm{MN} \cdot \mathrm{m} / \mathrm{m}$. Figure 8 shows the trend of the bending moment in the lining only due to the dynamic load with a variation of $\vartheta$ angle.

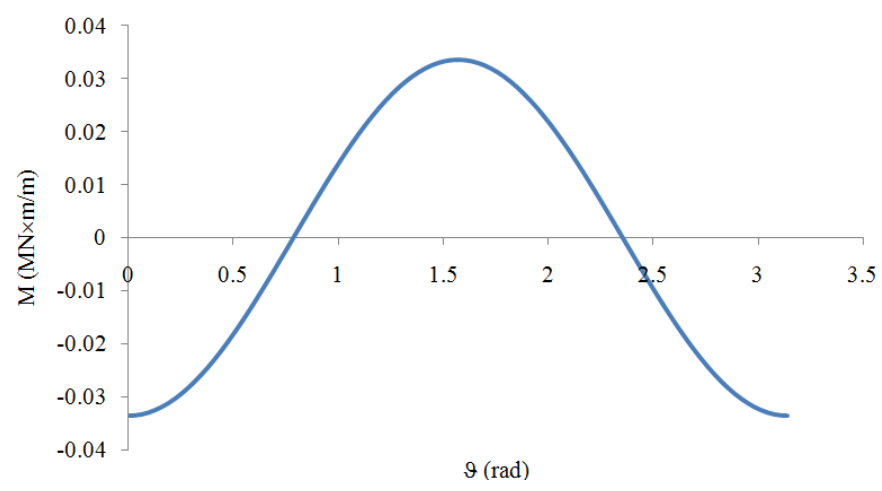

Fig. 7. Trend of the bending moment along the lining progress, for the studied case, with a variation of the $\vartheta$ angle $(\vartheta=0$ on the right side of the tunnel, $\vartheta$ increasing counterclockwise), in static conditions. The trend of the bending moment was calculated

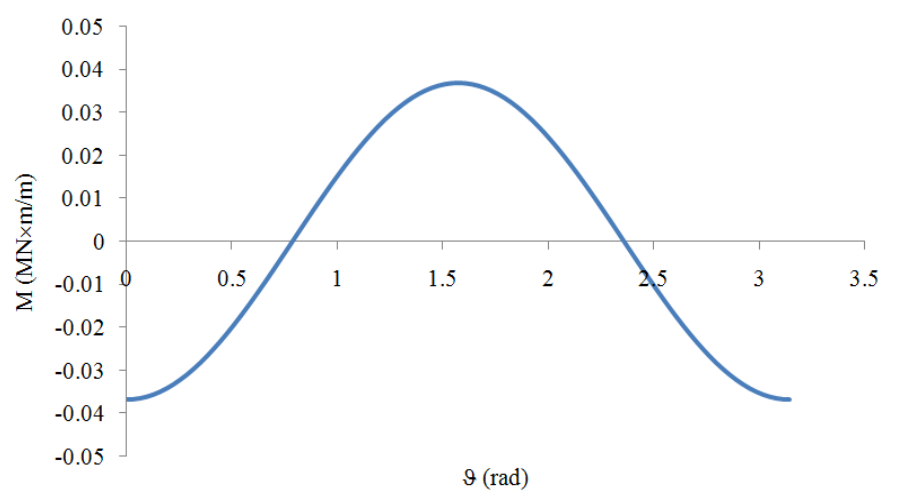

Fig. 8. Trend of the bending moment along the lining progress, for the studied case, with a variation of the $\vartheta$ angle $(\vartheta=0$ on the right side of the tunnel, $\vartheta$ increasing counterclockwise), in dynamic conditions. The trend of the bending moment was calculated by the Einstein and Schwartz (1979) method (full slip case) 


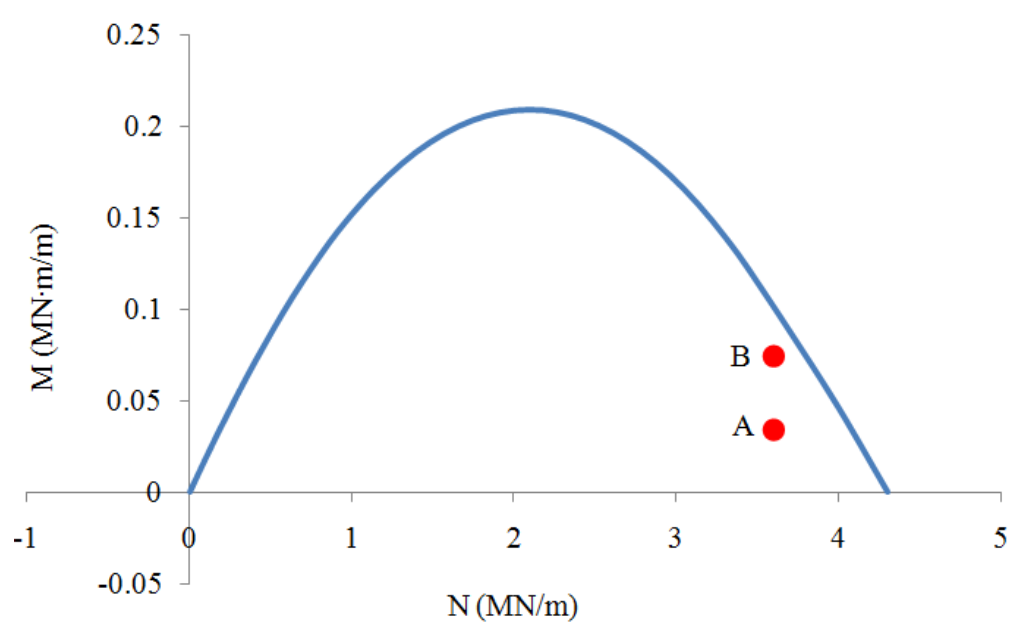

Fig. 9. Comparison of the lining stress state in static conditions (point A) and in static+dynamics conditions (point B), with the strength domain of the concrete section $(0.4 \mathrm{~m} \times 1 \mathrm{~m})$ in the absence of armature (blue solid line)

The value of the maximum moment due to dynamic loads is greater than the value of the maximum moment obtained in the static field. In order to verify the suitability of the assumed lining to bear the static and dynamic loads together, a comparison is necessary between the induced moments and axial forces obtained from the calculation and the concrete section strength (Fig. 9). In the present case and for the hypothesized earthquake, the assumed lining would be considered suitable to jointly withstand the loads produced by the earthquake and the static ones. Points A and B of Fig. 9 have the same value of the normal force, since the dynamic load produced by the earthquake had no effect on the axial forces that develop within the lining.

\section{Conclusion}

The verification of the ability of a tunnel lining to withstand the action of an earthquake is an important stage of the tunnel design. Detailed analysis of the interaction between the earthquake and the lining can be conducted with two-dimensional or threedimensional numerical methods. These methods, when used in the dynamic field, may require very long calculation times and for this reason a detailed numerical dynamic analysis is limited to the final configuration identified by the project.

In the field of tunnels, very useful are the analytical calculation methods, since they allow to obtain useful results with reduced calculation times. For this reason they are often used to develop parametric analyzes, probabilistic ones or back-analysis.

In this study is presented a simplified analytical procedure for the evaluation of the effect of an earthquake on the lining of a tunnel excavated in rock mass. This procedure has also allowed to evaluate, through an extensive parametric analysis, the pseudo- static loads that is necessary to consider in the calculations according to the type of earthquake and the qualitative characteristics of the rock mass. These results have been summarized in some abacuses easy to use.

A final example has shown the modalities to estimate the maximum bending moments in a tunnel lining due to an earthquake, using the abacuses developed in this study.

\section{Acknowledgement}

This research was performed with use of the equipment of the DIATI Department of Politecnico di Torino.

\section{Funding Information}

The authors have no support or funding to report.

\section{Ethics}

This article is original and contains unpublished material. The corresponding author confirms that all of the other authors have read and approved the manuscript and no ethical issues involved.

\section{References}

Cai, M., P.K. Kaiser, H. Uno, Y. Tasaka and M. Minami, 2004. Estimation of rock mass deformation modulus and strength of jointed hard rock masses using the GSI system. Int. J. Rock Mechan. Mining Sci., 41: 3-19. DOI: 10.1016/S1365-1609(03)00025-X

Do, N.A., D. Dias, P. Oreste and I. Djeran-Maigre, 2013. 2D numerical investigation of segmental tunnel lining behavior. Tunnell. Underground Space Technol., 37: 115-127.

DOI: $10.1016 /$ j.tust.2013.03.008 
Do, N.A., D. Dias, P. Oreste and I. Djeran-Maigre, 2014a. Three-dimensional numerical simulation for mechanized tunnelling in soft ground: The influence of the joint pattern. Acta Geotechn., 9: 673-694. DOI: $10.1007 / \mathrm{s} 11440-013-0279-7$

Do, N.A., D. Dias, P. Oreste and I. Djeran-Maigre, 2014b. Three-dimensional numerical simulation of a mechanized twin tunnels in soft ground. Tunnell. Underground Space Technol., 42: 40-51. DOI: $10.1016 /$ j.tust.2014.02.001

Do, N.A., D. Dias, P. Oreste and I. Djeran-Maigre, 2014c. A new numerical approach to the hyperstatic reaction method for segmental tunnel linings. Int. J. Numerical Analytical Methods Geomechan., 38: 1617-1632. DOI: $10.1002 /$ nag.2277

Do, N.A., D. Dias, P. Oreste and I. Djeran-Maigre, 2015. 2D numerical investigation of segmental tunnel lining under seismic loading. Soil Dynamics Earthquake Eng., 72: 66-76.

DOI: $10.1016 /$ j.soildyn.2015.01.015

Einstein, H.H. and C.W. Schwartz, 1979. Simplified analysis for tunnel supports. J. Geotechn. Eng. Division, 105: 499-518. cedb.asce.org/cgi/WWWdisplay.cgi?8742

El Naggar, H., S.D. Hinchberger and M.H. El Naggar, 2008. Simplified analysis of seismic in-plane stresses in composite and jointed tunnel linings. Soil Dynamics Earthquake Eng., 28: 1063-1077. DOI: $10.1016 /$ j.soildyn.2007.12.001

Hashash, Y.M.A., J.J. Hook, B. Schmidt and J.I. Yao, 2001. Seismic design and analysis of underground structures. Tunnell. Underground Space Technol., 16: 247-293. DOI: 10.1016/S0886-7798(01)00051-7

Hoek, E. and Brown E.T., 1980. Underground Excavations in Rock: The Institution of Mining and Metallurgy. 1st Edn., London, pp: 527.

Hoek E. and E.T. Brown, 1997. Practical estimates of rock mass strength. Int. J. Rock Mech. Mining Sci. 34: 1165-1186. DOI: $10.1016 / \mathrm{S} 1365-1609(97) 80069-\mathrm{X}$

Hoek, E., C. Carranza-Torres and B. Corkum, 2002. Hoek-Brown failure criterion-2002 edition. Proceedings of the NARMS-TAC Conference, (TAC' 02), Toronto, pp: 267-273.

Hoek, E., 2006. Practical rock engineering.

Hoek, E., 2007. A brief history of the development of the Hoek-Brown failure criterion. Soils and Rocks.

Hoek, E., T.G. Carter and M.S. Diederichs, 2013. Quantification of the geological strength index chart. Proceedings of the 47th US Rock Mechanics/Geomechanics Symposium, Jun. 23-26, San Francisco, CA, pp: 1-8.

Karakostas, C.Z. and G.D. Manolis, 2000. Dynamic response of unlined tunnels in soil with random properties. Eng. Struct., 22: 1013-1027. DOI: $10.1016 / \mathrm{S} 0141-0296(99) 00030-9$
Lembo-Fazio, A. and R. Ribacchi, 1986. Stato di sforzo e deformazione intorno ad una galleria. Torino, Italy.

Marinos, P. and E. Hoek, 2000. GSI: A geologically friendly tool for rock mass strength estimation. Proceedings of the International Conference on Geotechnical and Geological Engineering, Nov. 19-24, Melbourne, pp: 1-17.

Marinos, V., P. Marinos and E. Hoek, 2005. The geological strength index: Applications and limitations. Bull Eng. Geol. Environ. 64: 55-65. DOI: $10.1007 / \mathrm{s} 10064-004-0270-5$

Oreste, P.P., 2002. The importance of longitudinal stress effects on the static conditions of the final lining of a tunnel. Tunnell. Underground Space Technol., 17: 21-32.

Oreste, P.P., 2003a. Analysis of structural interaction in tunnels using the convergence-confinement approach. Tunnell. Underground Space Technol., 18: 347-363. DOI: 10.1016/S0886-7798(03)00004-X

Oreste, P.P., 2003b. A procedure for determining the reaction curve of shotcrete lining considering transient conditions. Rock Mechan. Rock Eng., 36: 209-236. DOI: 10.1007/s00603-002-0043-z

Oreste, P., 2005a. A probabilistic design approach for tunnel supports. Comput. Geotechn., 32: 520-534. DOI: 10.1016/j.compgeo.2005.09.003

Oreste, P., 2005b. Back-analysis techniques for the improvement of the understanding of rock in underground constructions. Tunnell. Underground Space Technol., 20: 7-21.

DOI: $10.1016 /$ j.tust.2004.04.002

Oreste, P.P., 2007. A numerical approach to the hyperstatic reaction method for the dimensioning of tunnel supports. Tunnell. Underground Space Technol., 22: 185-205.

DOI: $10.1016 /$ j.tust.2006.05.002

Oreste, P., 2008. Distinct analysis of fully grouted bolts around a circular tunnel considering the congruence of displacements between the bar and the rock. Int. J. Rock Mechan. Mining Sci., 45: 1052-1067. DOI: 10.1016/j.ijrmms.2007.11.003

Oreste, P., 2009a. The convergence-confinement method: Roles and limits in modern geomechanical tunnel design. Am. J. Applied Sci., 6: 757-771. DOI: 10.3844/ajassp.2009.757.771

Oreste, P.P., 2009b. Face stabilisation of shallow tunnels using fibreglass dowels. Proc. Institut. Civil Eng. Geotechn. Eng., 162: 95-109. DOI: 10.1680/geng.2009.162.2.95

Oreste, P., 2013. Face stabilization of deep tunnels using longitudinal fibreglass dowels. Int. J. Rock Mechan. Mining Sci., 58: 127-140. DOI: 10.1016/j.ijrmms.2012.07.011

Oreste, P., 2014a. Evaluation of the tunnel face stability through a ground stress analysis with a hemispherical geometry approximation. Am. J. Applied Sci., 11: 1995-2003.

DOI: 10.3844/ajassp.2014.1995.2003 
Oreste, P., 2014b. A numerical approach for evaluating the convergence-confinement curve of a rock tunnel considering hoek-brown strength criterion. Am. J. Applied Sci., 11: 2021-2030.

DOI: 10.3844/ajassp.2014.2021.2030

Oreste, P., 2014c. The determination of the tunnel structure loads through the analysis of the interaction between the void and the support using the convergence-confinement method. Am. J. Applied Sci., 11: 1945-1954.

DOI: 10.3844 /ajassp.2014.1945.1954

Osgoui, R.R. and P. Oreste, 2007. Convergence-control approach for rock tunnels reinforced by grouted bolts, using the homogenization concept. Geotechn. Geol. Eng., 25: 431-440.

DOI: $10.1007 / \mathrm{s} 10706-007-9120-0$

Osgoui, R.R. and P. Oreste, 2010. Elasto-plastic analytical model for the design of grouted bolts in a Hoek-Brown medium. Int. J. Numerical Analytical Methods Geomechan., 34: 1651-1686. DOI: $10.1002 /$ nag. 823

Panet, M., 1995. Le calcul des tunnels par la méthode convergence-confinement. Infoscience.
Penzien, J. and C.L. Wu, 1998. Stresses in linings of bored tunnels. Earthquake Eng. Structural Dynamics, 27: 283-300. DOI: 10.1002/(SICI)10969845(199803)27:3<283::AID-EQE732>3.0.CO;2-T

Penzien, J., 2000. Seismically induced racking of tunnel linings. Earthquake Eng. Struct. Dynamics, 29: 683-691. DOI: 10.1002/(SICI)10969845(200005)29:5<683::AID-EQE932>3.0.CO;2-1

Power, M., K. Fishman, R. Richards, F. Makdisi and S. Musser et al., 2004. Seismic retrofitting manual for highway structures: Part 2-retaining structures, slopes, tunnels, culverts and roadways. Department of Transportation.

Ribacchi, R. and R. Riccioni, 1977. Stato di sforzo e deformazione intorno ad una galleria circolare. Gallerie e Grandi Opere Sotterranee, 5: 7-18.

Sadigh and Egan, 1998. Updated relationships for horizontal peak ground velocity and peak ground displacement for shallow crustal earthquakes. Proceedings of the 6th U.S. National Conference on Earthquake Engineering, (CEE' 98), Seattle, Washington. 